\title{
The ferric uptake regulator of Pseudomonas aeruginosa has no essential cysteine residues and does not contain a structural zinc ion
}

\author{
Allison C. Lewin, ${ }^{1,2}$ Phillip A. Doughty, ${ }^{1}+$ Lynda Flegg, ${ }^{1}$ \\ Geoffrey R. Moore ${ }^{2}$ and Stephen Spiro ${ }^{1}$
}

School of Biological Sciences ${ }^{1}$ and School of Chemical Sciences², University of East Anglia, Norwich NR4 7TJ, UK
Author for correspondence: Stephen Spiro. Tel: +44 1603 593222. Fax: +44 1603592250. e-mail:s.spiro@uea.ac.uk

The ferric uptake regulator (Fur) of Pseudomonas aeruginosa was expressed in Escherichia coli in its native form and as a fusion to the maltose-binding protein (MBP). Fur from the MBP fusion bound to MBP after proteolytic cleavage, and the two could only be separated by partial unfolding. The refolded protein was in the same conformation as native protein (as judged by circular dichroism and fluorescence spectroscopies) and was fully active in DNA-binding assays. As-prepared native Fur contained small amounts of $\mathbf{Z n}^{\mathbf{2 +}}$ that were easily removed by treatment with EDTA, and apo-protein could be reconstituted with approximately one $\mathrm{Zn}^{2+}$ ion per monomer. Thus, the $P$. aeruginosa Fur can probably accommodate a single $\mathrm{Zn}^{2+}$ ion bound to the metal-sensing site. The single cysteine residue of $P$. aeruginosa Fur aligns with a cysteine in other members of the Fur family that is essential for activity of the $E$. coli protein, and is believed to provide one of the ligands to a structural $\mathrm{Zn}^{2+}$ ion. This cysteine residue was shown to be dispensable for the in vivo activity of $P$. aeruginosa Fur, which is consistent with the suggestion that the $P$. aeruginosa protein does not contain a structural $\mathrm{Zn}^{2+}$ ion. Members of the Fur family contain a highly conserved His-His-Asp-His motif. Alanine substitutions of residues in this motif showed His-87 and His-89 of $P$. aeruginosa Fur to be essential for activity, whilst His-86 and Asp-88 are partially dispensable.

Keywords: Fur, iron regulation

\section{INTRODUCTION}

The ferric uptake regulator (Fur) is a widespread bacterial protein that regulates the expression of iron acquisition and storage systems in response to intracellular iron (Escolar et al., 1999). Fur is a key regulator of iron metabolism, but in different organisms it clearly has roles in numerous other aspects of physiology (Escolar et al., 1999). In the enteric bacteria, such as Escherichia coli and Salmonella enterica, members of the Fur regulon include siderophore synthesis and uptake genes, as well as genes involved in carbon metabolism and responses to oxidative stress (Escolar et

\footnotetext{
†Present address: School of Biological Sciences, University of Sussex, Falmer, Brighton BN1 9QG, UK.

Abbreviations: $\mathrm{CD}$, circular dichroism; $\mathrm{Gdn} . \mathrm{HCl}$, guanidinium hydrochloride; MBP, maltose-binding protein.
}

al., 1999). There is also genetic evidence to suggest that Fur has a role in acid tolerance (Hall \& Foster, 1996). Besides acting as a classical iron-dependent repressor of protein-coding genes, it has recently been found that the E. coli Fur also represses expression of a small regulatory RNA designated RhyA. RhyA itself down-regulates the expression of genes encoding proteins involved in iron storage and utilization (Massé \& Gottesman, 2002). The discovery of RhyA provides a rationale for the apparent ability of Fur to work as an activator, and for the early observation that fur mutants of E. coli are unable to grow on succinate (Massé \& Gottesman, 2002; Hantke, 1987).

Iron acquisition is a particular problem for pathogenic bacteria, since the bioavailability of iron in the host is often especially low. Hence, there is often a need for iron acquisition systems to be switched on when the pathogen encounters a host environment (Litwin \& Calderwood, 
1993; Ratledge \& Dover, 2000). Furthermore, there is good evidence to indicate that iron limitation is used, in some cases, as a signal to activate the expression of virulence genes, and that this regulation can ultimately depend on Fur. One example is the opportunistic pathogen Pseudomonas aeruginosa, in which Fur regulates the expression of the alternative sigma factor encoded by the $p v d S$ gene, which is in turn required for the transcription of some virulence genes, including those encoding the endoprotease PrpL and exotoxin A (Leoni et al., 1996; Wilderman et al., 2001; Ochsner et al., 1996; reviewed by Vasil \& Ochsner, 1999).

Genetic characterization of fur mutants, and biochemical analysis of the Fur protein, suggested that the active species is a dimer with one $\mathrm{Fe}^{2+}$ ion bound to each monomer. Results from proteolysis and gene-fusion experiments indicated that the protein folds into an $\mathrm{N}$ terminal DNA-binding domain and a C-terminal metalbinding and dimerization domain (Coy \& Neilands, 1991; Stojiljkovic \& Hantke, 1995). Early models for the mode of action of Fur had the protein functioning as a classical repressor, with the $\mathrm{Fe}^{2+}$ ion acting as corepressor. This simple view has been challenged by two recent developments. The first of these is the identification of a structural $\mathrm{Zn}^{2+}$ ion in the E. coli protein that is apparently required for DNA binding, and is bound to a site distinct from the metal-sensing site (Jacquamet et al., 1998; Gonzalez de Peredo et al., 1999; Althaus et al., 1999). Secondly, it has been suggested that the binding of Fur to DNA is directly inhibited by EDTA, which may require the conclusions of some earlier experiments to be re-evaluated (Althaus et al., 1999). E. coli Fur containing the structural $\mathrm{Zn}^{2+}$ ion and with a vacant metal-sensing site has been shown to bind to DNA with high affinity, which may even call into question the role of $\mathrm{Fe}^{2+}$ as co-repressor (Althaus et al., 1999). In this context, it is interesting that the Bacillus subtilis Fur apparently does not require $\mathrm{Fe}^{2+}$ for DNA binding activity in vitro (Bsat \& Helmann, 1999). Ligands to the structural $\mathrm{Zn}^{2+}$ ion are believed to include Cys-92 and Cys-95, which have been shown to be essential for normal Fur activity in E. coli (Coy et al., 1994; Gonzalez de Peredo et al., 1999). Indeed, amongst a collection of Fur proteins substituted at all cysteine and histidine residues, those in which Cys-92 or Cys-95 were replaced by serine had much the most severe phenotypes (Coy et al., 1994). These two cysteines are conserved in, for example, the Fur proteins of Vibrio anguillarum and Bacillus subtilis, which are also thought to contain a structural $\mathrm{Zn}^{2+}$ ion (Bsat \& Helmann, 1999; Zheleznova et al., 2000). On the other hand, only Cys-92 is conserved in some presumed Fur orthologues, including that from $P$. aeruginosa, and in other cases (such as Pseudomonas putida), neither cysteine is conserved. This raises the possibility of structural and/or mechanistic diversity in the Fur family, perhaps with some members not requiring a structural $\mathrm{Zn}^{2+}$ ion for activity (Zheleznova et al., 2000). As a first step in exploring whether sequence diversity is reflected in the biochemical properties of Fur proteins, the Fur from $P$. aeruginosa has been further characterized. It is shown that this protein does not contain a structural $\mathrm{Zn}^{2+}$ ion, and that its single cysteine residue is not essential for activity in vivo. Two histidine residues essential for $P$. aeruginosa Fur activity are also identified.

\section{METHODS}

Bacterial strains, plasmids and growth conditions. The strains of E. coli used were JRG2653 $\Delta$ ara $\Delta(\arg F-l a c)$ rpsL relA deoC ptsF $\Delta$ fur $\lambda b f d-l a c Z$ and its isogenic fur ${ }^{+}$parent JRG2652 (both gifts from Simon Andrews, University of Reading, UK), BL21 omp T gal dcm hsdS $S_{\mathrm{B}}(\lambda \mathrm{DE} 3$ ) for expression of pET21a clones, and JM83 lacZ lacl $\phi 80$ slacZM15 for routine DNA manipulations and expression of the maltose-binding protein (MBP)-Fur fusion protein. The strain of $P$. aeruginosa used was PAO1 (from Richard James, University of Nottingham, UK). The plasmids used were pUC18 for routine cloning procedures, pET21a (Novagen) for overexpression, and pMALc2 (New England Biolabs) for construction of a malE-fur fusion. Routine growth of bacteria was in Lennox broth (tryptone $10 \mathrm{~g} \mathrm{l}^{-1}$, yeast extract $5 \mathrm{gl}^{-1}, \mathrm{NaCl} 5 \mathrm{gl}^{-1}$ ). For assay of $\beta$-galactosidase, E. coli strains were grown in M9 minimal medium (Miller, 1992), supplemented as indicated with $50 \mu \mathrm{M} \mathrm{Fe}(\mathrm{III})$ citrate or with $20 \mu \mathrm{M}$ bipyridyl.

DNA manipulations. The $P$. aeruginosa fur gene was amplified from chromosomal DNA purified from strain PAO1, using a primer $\left(5^{\prime}\right.$-CATATGGTTGAAAATAGCGAACTT-3') that incorporated an $\mathrm{Nde}$ I site at the start codon (underlined) of the coding region. The PCR product was cloned into pUC18, and sequenced to check that mutations had not been introduced. The fur gene was then excised from this clone using the vector PvuII sites and was blunt-end cloned into the $S c a$ I site of pBR322 to generate pPAD24. The fur gene in pPAD24 is expressed from the lac promoter derived from pUC18, and the lower-copy-number vector was found to be required for stable maintenance of the clone. Mutations were introduced into a clone of the fur gene in pUC18 by a PCR-based method (Hutchings et al., 2000); mutant genes were sequenced twice to confirm that the correct mutation had been introduced, and were then cloned on PvuII fragments into the ScaI site of pBR322. The NdeI-EcoRI fragment from the pUC18 fur clone was cloned into pET21a to generate a clone suitable for overexpression in BL21( $2 \mathrm{DE} 3)$. For construction of an MBPFur fusion, fur was amplified by PCR using a $5^{\prime}$ primer $\left(5^{\prime}\right.$ GGGAATTCATGGTTGAAAATAGCGAACT-3') incorporating an EcoRI site immediately upstream of the start codon (underlined). PCR products were blunt-end cloned into SmaI-digested pUC18, and, from a clone in the correct orientation, fur was excised on an EcoRI-BamHI fragment (using the vector BamHI site) and cloned into pMAL-c2 (New England Biolabs). The intermediate pUC18 clone was sequenced to ensure that no mutations had been introduced. This procedure fused fur in-frame to malE; the gene fusion is predicted to encode a protein that adds the sequence Ile-SerGlu-Phe on to the N-terminus of Fur after cleavage with factor $\mathrm{Xa}$.

Protein purification. Fur was purified from the pET21 clone in BL21(2DE3) initially using the method of Ochsner et al. (1995). Subsequently a modified procedure was developed, which did not involve metal-affinity chromatography. Cultures $(500 \mathrm{ml})$ were grown to an $\mathrm{OD}_{650}$ of $0 \cdot 5-0 \cdot 6$, induced with $1 \mathrm{mM}$ IPTG, then incubated overnight. Cells were harvested, washed in $50 \mathrm{mM}$ Tris/ $\mathrm{HCl}$ (pH 7.9) $-0.5 \mathrm{mM}$ EDTA-50 $\mathrm{mM} \mathrm{NaCl}$, then resuspended in the same buffer containing $1 \mathrm{mM}$ PMSF and $1 \mathrm{mM}$ DTT. After sonication, the 
cell-free extract was applied to a $300 \mathrm{ml}$ DEAE cellulose ionexchange column equilibrated with $50 \mathrm{mM}$ Tris $/ \mathrm{HCl}$ (pH 7.9)-50 mM NaCl, and then eluted with a linear 50$500 \mathrm{mM} \mathrm{NaCl}$ gradient in the same buffer. Fur-containing fractions (as judged by SDS-PAGE) were dialysed overnight in $20 \mathrm{mM}$ Tris $/ \mathrm{HCl}(\mathrm{pH} 7 \cdot 0)$ then applied to a $20 \mathrm{ml}$ heparinagarose column equilibrated with $20 \mathrm{mM}$ Tris/ $\mathrm{HCl}(\mathrm{pH} 7 \cdot 0)$. The column was washed with the same buffer, then Fur was eluted with $20 \mathrm{mM}$ Tris/ $\mathrm{HCl}(\mathrm{pH} 7 \cdot 0)-1 \mathrm{M} \mathrm{NaCl}$.

For purification of the MBP fusion, $500 \mathrm{ml}$ cultures were grown in Lennox broth containing $0.2 \%(\mathrm{w} / \mathrm{v})$ glucose to an $\mathrm{OD}_{650}$ of $0 \cdot 5-0 \cdot 6$, induced with $1 \mathrm{mM}$ IPTG, then incubated overnight. Cells were harvested, washed in $50 \mathrm{mM}$ Tris $/ \mathrm{HCl}$ $(\mathrm{pH} 7 \cdot 9)-50 \mathrm{mM} \mathrm{NaCl}$, then resuspended in the same buffer containing $0.5 \mathrm{mM}$ EDTA, $1 \mathrm{mM}$ PMSF and $1 \mathrm{mM}$ DTT. Cells were disrupted by sonication, clarified, and the cell extract applied to a $15 \mathrm{ml}$ amylose column equilibrated with $50 \mathrm{mM}$ Tris/ $\mathrm{HCl}$ (pH 7.9) $-100 \mathrm{mM} \mathrm{NaCl}$. The column was washed with the same buffer, then the fusion protein eluted with $50 \mathrm{mM}$ Tris $/ \mathrm{HCl}$ (pH 7.9)-100 mM NaCl-10 mM maltose. The fusion was treated with factor $\mathrm{Xa}$, and then $3 \mathrm{M}$ guanidinium hydrochloride $(\mathrm{Gdn} . \mathrm{HCl})$. The partially denatured Fur was purified by FPLC on an S75 gel-filtration column, then renatured by dialysis against $20 \mathrm{mM}$ Tris/ $\mathrm{HCl}$ (pH 7·0)-50 mM NaCl.

DNA-binding assays. For use in gel retardation assays, a $300 \mathrm{bp}$ fragment of the $P$. aeruginosa $p v d S$ promoter region was amplified by PCR and cloned into the SmaI site of pUC18. The fragment extended $315 \mathrm{bp}$ upstream of the $p v d S$ start codon, not including the $14 \mathrm{bp}$ immediately $5^{\prime}$ to the ATG. Thus, the fragment included the $p v d S-35$ and -10 sequences, and a predicted Fur-binding site overlapping the -35 sequence (Ochsner et al., 1995). This fragment was excised with EcoRI and HindIII (using the vector sites, generating a fragment of total size $350 \mathrm{bp}$ ) and was labelled by end-filling with DNA polymerase I in the presence of $\left[{ }^{35} \mathrm{~S}\right] \mathrm{dATP} \alpha \mathrm{S}$. The procedure for gel retardation assays was modified from that of Althaus et al. (1999). Binding buffer $(5 \times$ concentrate $)$ contained $100 \mathrm{mM}$ Tris $/ \mathrm{HCl}(\mathrm{pH} 7 \cdot 0), 25 \%$ (v/v) glycerol, $10 \mu \mathrm{g}$ herring sperm DNA $\mu^{-1}, 5 \mathrm{mM} \mathrm{MgCl}, 200 \mathrm{mM} \mathrm{KCl}$ and $500 \mu \mathrm{g}$ bovine serum albumin $\mathrm{ml}^{-1}$, and was supplemented with $\mathrm{MnCl}_{2}$ as required. Binding reactions contained $2 \mu \mathrm{l} 5 \times$ binding buffer, $1 \mu \mathrm{l}$ radiolabelled DNA, Fur to the desired final concentration, and distilled water to a final reaction volume of $10 \mu \mathrm{l}$. The binding reaction was left at room temperature for 20-30 min before loading on to a $6 \%$ polyacrylamide gel. The gel was made up in $20 \mathrm{mM}$ Tris, buffered to $\mathrm{pH} 7 \cdot 0$ with boric acid, and was run at $120 \mathrm{~V}$ for $80 \mathrm{~min}$. The gel was transferred to $3 \mathrm{MM}$ Whatman paper, dried, and exposed to a Molecular Dynamics phosphorimager screen overnight. The screen was digitized and quantified using a Storm 840 laser scanner (Molecular Dynamics) and images were visualized and quantified using ImageQuant version 5.0 (Molecular Dynamics).

Spectroscopy. Fluorescence emission spectra were recorded on a Perkin Elmer LS50 fluorimeter using an excitation wavelength of $290 \mathrm{~nm}$ and excitation and emission slits of 5 $\mathrm{nm}$. Scan speed was $1000 \mathrm{~nm} \mathrm{~min}{ }^{-1}$ and a mean of 10 scans was recorded. Both proteins were $13 \mu \mathrm{M}$ in $20 \mathrm{mM}$ Tris/ $\mathrm{HCl}$ ( $\mathrm{pH}$ 8)-50 mM NaCl, and emission spectra of the buffer were subtracted. Circular dichroism (CD) spectra were collected on a Jasco J-710 spectropolarimeter with a scan speed of $100 \mathrm{~nm}$ $\mathrm{min}^{-1}$ and a path length of $0.2 \mathrm{~mm}$. Each sample was scanned three times, and a mean spectrum calculated. Fur samples were at $0 \cdot 3-0.9 \mathrm{mg} \mathrm{ml}^{-1}$ in $20 \mathrm{mM}$ Tris/ $\mathrm{HCl}(\mathrm{pH} \mathrm{8.0)}-50 \mathrm{mM}$ $\mathrm{NaCl}$. The observed ellipticity in millidegrees $(\theta)$ was con- verted to mean residue molar ellipticity $(\theta)_{\mathrm{MR}}$ in $\operatorname{deg} \mathrm{cm}^{2} \mathrm{dmol}^{-1}$ residue $^{-1}$ according to equation 1 :

$(\theta)_{\mathrm{MR}}=\left(\theta \times 10^{-4} M_{\mathrm{r}}\right) /($ c.l.n $)$

where $M_{\mathrm{r}}$ is the relative molecular mass of the protein, $c$ is the concentration in $\mathrm{g} \mathrm{ml}^{-1}, l$ is the path length in $\mathrm{cm}$, and $n$ is the number of residues.

Protein unfolding. Protein samples $\left(0 \cdot 14 \mathrm{mg} \mathrm{ml}^{-1}\right)$ were dialysed for $4 \mathrm{~h}$ at room temperature against varying $\mathrm{Gdn} . \mathrm{HCl}$ concentrations, then incubated at $37^{\circ} \mathrm{C}$ for a further $1 \mathrm{~h}$ before recording CD spectra as above. Baselines collected at the relevant $\mathrm{Gdn} . \mathrm{HCl}$ concentrations were subtracted. The ellipticity at $222 \mathrm{~nm}(\theta)$ was used to calculate the fraction of unfolded protein $\left(f_{\mathrm{u}}\right)$ according to equation 2 :

$f_{u}=\left(\theta-\theta_{\mathrm{n}}\right) /\left(\theta_{\mathrm{u}}-\theta_{\mathrm{n}}\right)$

where $\theta_{\mathrm{u}}$ is the ellipticity at $222 \mathrm{~nm}$ of the fully denatured protein and $\theta_{\mathrm{n}}$ is the ellipticity at $222 \mathrm{~nm}$ of the native protein. Data points were corrected for the slopes of the pre- and posttransitional regions of the curves using linear regression (Santoro \& Bolen, 1988; Pace \& Scholtz, 1997). The fraction of unfolded protein $\left(f_{\mathrm{u}}\right)$ was plotted against [Gdn] and the resultant curves fitted to equation (3) using Fig.P v2.98 (BIOSOFT) :

$f_{\mathrm{u}}=\frac{\exp \left\{m\left([\mathrm{Gdn}]-[\mathrm{Gdn}]_{0 \cdot 5}\right)\right\} / \boldsymbol{R} T}{1+\exp \left\{m\left([\mathrm{Gdn}]-[\mathrm{Gdn}]_{0 \cdot 5}\right)\right\} / \boldsymbol{R} T}$

where $[\mathrm{Gdn}]_{0.5}$ is the concentration of $\mathrm{Gdn} . \mathrm{HCl}$ at which the protein is $50 \%$ unfolded, and $m$ is the rate of change of free energy with respect to [Gdn].

Analytical techniques. Electrospray mass spectrometry was done on a Micromass Platform I mass spectrometer calibrated with horse heart myoglobin. The solvent was $50 \%(\mathrm{v} / \mathrm{v})$ acetonitrile and $0 \cdot 1 \%(\mathrm{v} / \mathrm{v})$ formic acid in water, and samples were run at a rate of $20 \mu \mathrm{lmin}^{-1}$. For electrothermal atomic absorption spectroscopy, all glassware was washed in $10 \%$ $(\mathrm{v} / \mathrm{v})$ nitric acid, and rinsed thoroughly in triple-distilled water followed by Milli-Q water. Fur was dialysed overnight against $50 \mathrm{mM}$ Tris/HCl (pH 8.0)-50 mM EDTA-200 mM $\mathrm{NaCl}$, then dialysed extensively against $50 \mathrm{mM}$ Tris $/ \mathrm{HCl}$ (pH 8.0)-200 mM NaCl. To assay zinc binding, $1 \mathrm{ml}$ samples containing $10 \mu \mathrm{M}$ Fur in $50 \mathrm{mM}$ Tris/HCl (pH 8.0)-200 mM $\mathrm{NaCl}$ were made to $150 \mu \mathrm{M} \mathrm{ZnCl}_{2}$, and left overnight at $4{ }^{\circ} \mathrm{C}$, before the dialysis against $200 \mathrm{mM} \mathrm{NaCl}$ was repeated. All samples and $\mathrm{ZnCl}_{2}$ standards were passed through a $0 \cdot 2 \mu \mathrm{m}$ filter before analysis on a Philips PU9200 atomic absorption spectrophotometer with an electrographite cuvette. Absorption was at $213.9 \mathrm{~nm}$ with a $0.5 \mathrm{~nm}$ bandpass, and each sample was measured five times. Protein concentrations were determined with a bicinchoninic acid assay kit (Sigma), or using an absorption coefficient $\left(280 \mathrm{~nm}\right.$ ) of $4218 \mathrm{M}^{-1} \mathrm{~cm}^{-1}$ estimated for the protein cleaved from the MBP fusion according to the method of Gill \& von Hippel (1989). $\beta$-Galactosidase was assayed according to the method of Miller (1992). DNA sequences were determined by MWG Biotech (Germany).

\section{RESULTS AND DISCUSSION}

\section{Expression, purification and biophysical characterization of $P$. aeruginosa Fur}

The $P$. aeruginosa fur gene was amplified and cloned into pET21a, with a view to achieving a high level of expression for subsequent purification. Expression of 


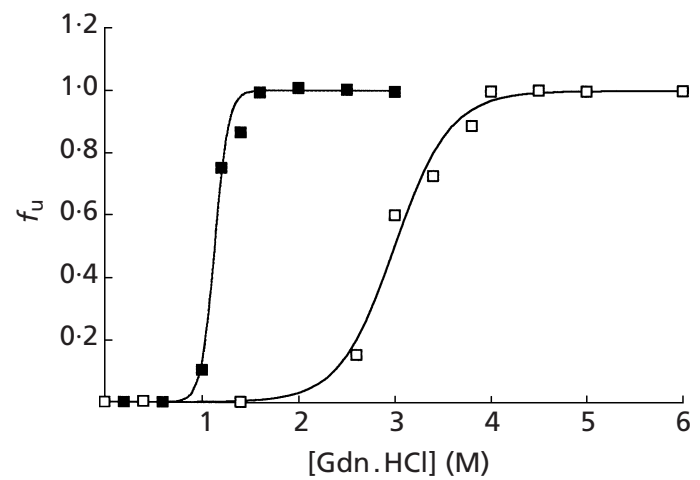

Fig. 1. Unfolding of MBP and Fur purified from the MBP-Fur fusion. $\square$, Unfolding profile of MBP (which lacks 26 residues at the $\mathrm{N}$-terminus and has a 21-residue C-terminal extension compared to wild-type MBP). $\square$, Unfolding profile of Fur (which has an N-terminal tetrapeptide extension Ile-Ser-GluPhe). The fraction of protein unfolded $\left(f_{\mathrm{u}}\right.$, where 1 represents complete unfolding) was calculated according to equation 2 (see Methods), and the curves were fitted to the data points using equation 3 .

Fur was indeed at a high level, and protein could be purified by following the method of Ochsner et al. (1995), involving ion-exchange and copper-affinity chromatographies. This purification protocol proved to be poorly reproducible, so an alternative method was devised (see Methods) involving anion-exchange, followed by affinity chromatography on heparin-agarose, yielding $16 \mathrm{mg}$ pure protein from a $3 \mathrm{l}$ culture. Electrospray mass spectrometry of the purified material gave an estimated mass of $15232 \mathrm{Da}$, in good agreement with the mass predicted from sequence $(15235 \mathrm{Da})$. One longterm goal of Fur expression was to provide isotopically labelled material for NMR analysis of the protein structure. For this purpose, the yield was rather low, so protein fusion methods were investigated as an alternative approach to Fur expression and purification.

In the first instance, the maltose-binding protein (MBP) was chosen for fusion to Fur, since MBP has previously been used successfully for making fusions to transcriptional regulators (Chai \& Stewart, 1998; Li et al., 1994). The fur gene was fused to the malE gene encoding MBP in the vector pMALc2. This procedure fused Fur to the C-terminus of a derivative of MBP from which the signal peptide has been deleted. The fusion protein was purified by affinity chromatography on an amylose resin and was cleaved with factor Xa. Following cleavage with factor $\mathrm{Xa}$ (confirmed by SDS-PAGE), Fur and MBP co-eluted in a number of chromatographic separations (amylose affinity, heparin affinity and ion exchange), indicating the formation of a complex between the cleaved Fur and MBP. Some free MBP (but no Fur) was always seen in these preparations, suggesting a stoichiometric excess of Fur in the complex, which is consistent with an oligomeric form of Fur binding to MBP. A similar postcleavage interaction has been observed with a fusion of the cystic fibrosis transmembrane regulator to $\mathrm{MBP}$ (Ko et al., 1993).

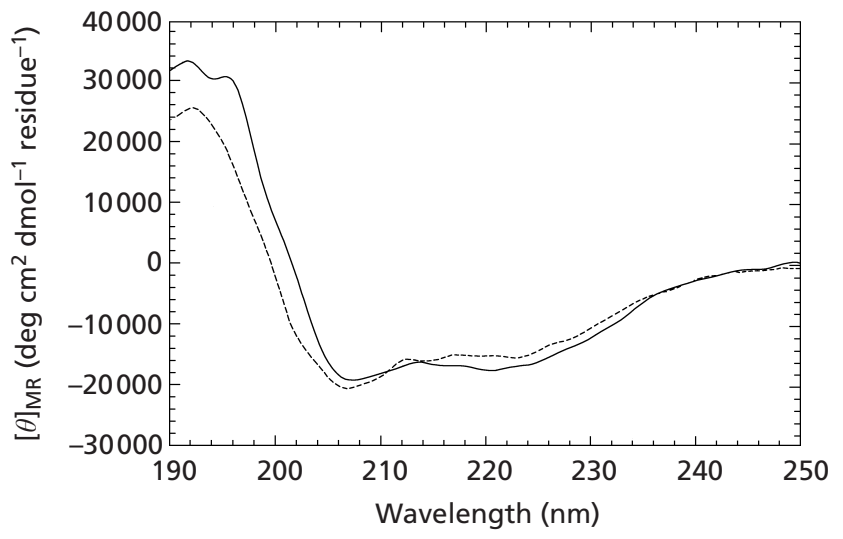

Fig. 2. $C D$ spectroscopy of recombinant Fur protein purified from an MBP fusion and from the native pET21a expression clone. The native Fur (dashed line) was at $0.5 \mathrm{mg} \mathrm{ml}^{-1}$, and the protein cleaved from the MBP fusion (solid line) at 0.28 $\mathrm{mg} \mathrm{ml}^{-1}$, in $20 \mathrm{mM}$ Tris/ $\mathrm{HCl}$ (pH 8.0)-50 mM NaCl.

Separation of Fur from MBP was achieved by exploiting their different stabilities in Gdn.HCl. MBP was $50 \%$ unfolded with $1 \cdot 1 \mathrm{M} \mathrm{Gdn} . \mathrm{HCl}$, while Fur required $3 \cdot 2 \mathrm{M}$ Gdn.HCl for $50 \%$ unfolding (Fig. 1). The mixture containing Fur and MBP was treated with $3 \mathrm{M}$ Gdn.HCl, and the partially unfolded Fur was separated from the unfolded MBP by gel filtration. Subsequent removal of the $\mathrm{Gdn} . \mathrm{HCl}$ by dialysis yielded Fur that was active, as judged by its ability to bind to DNA (see below). The yield of protein from this procedure was $30 \mathrm{mg}$ from 1.51 of culture. Electrospray mass spectrometry gave an estimated mass of $15709 \mathrm{Da}$, close to the predicted mass of $15711 \mathrm{Da}$ for the protein that has the sequence Ile-Ser-Glu-Phe added to its N-terminus as a result of the cloning procedure. Some of the biochemical experiments reported below were done with material prepared in this way, and protein preparations from the two different sources were indistinguishable by all criteria tested.

The CD spectrum (Fig. 2) of Fur purified from the clone in pET21a is indicative of a high degree of $\alpha$-helical content. Deconvolution of the spectrum with the program CDNN (http://bioinformatik.biochemtech.unihalle.de/cd_spec/download.html) suggests a secondary structure content of $49 \% \alpha$-helix, $9 \cdot 1 \% \quad \beta$-sheet, $15.5 \%$ $\beta$-turn and $17.8 \%$ random coil. The CD spectrum of the protein purified from the MBP fusion is similar (Fig. 2), and gives similar estimates of secondary structure content. Both proteins emitted a similar fluorescence maximum centred at $\sim 350 \mathrm{~nm}$ on excitation at $290 \mathrm{~nm}$ (Fig. 3). Since Fur lacks tryptophan, this fluorescence must arise from a tyrosinate ion, as there is no other amino acid fluorophore reported to have this behaviour (Lakowicz, 1983). Although the $\mathrm{p} K_{\mathrm{a}}$ of the hydroxyl group of tyrosine is $\sim 10.3$ in its electronic ground state, it can decrease to $<4$ upon excitation and give fluorescence of the type seen here for Fur. Studies of this phenomenon in other proteins have shown that tyrosinate fluorescence reflects the three-dimensional struc- 


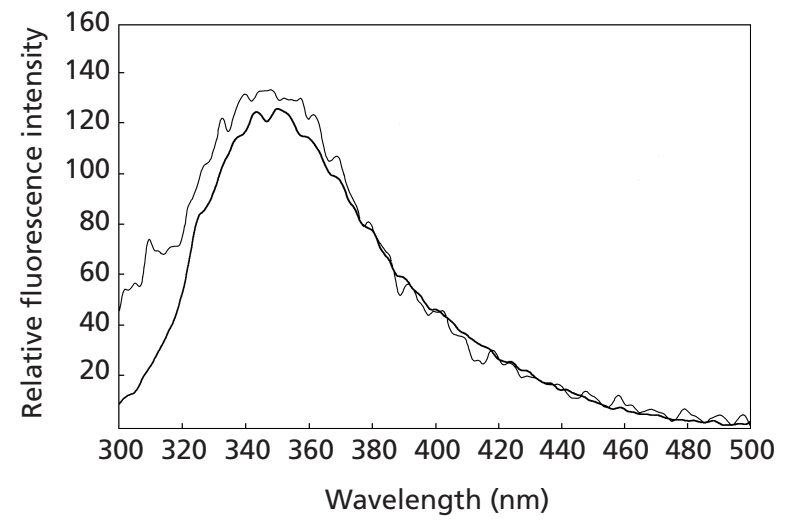

Fig. 3. Fluorescence emission spectra of Fur. In both cases protein concentration was $13 \mu \mathrm{M}$ in $20 \mathrm{mM}$ Tris/ $\mathrm{HCl}$ (pH 8)$50 \mathrm{mM} \mathrm{NaCl}$, and excitation was at $290 \mathrm{~nm}$. Fur was purified from the native pET21 expression clone (thin line) and from the MBP fusion (thicker line).

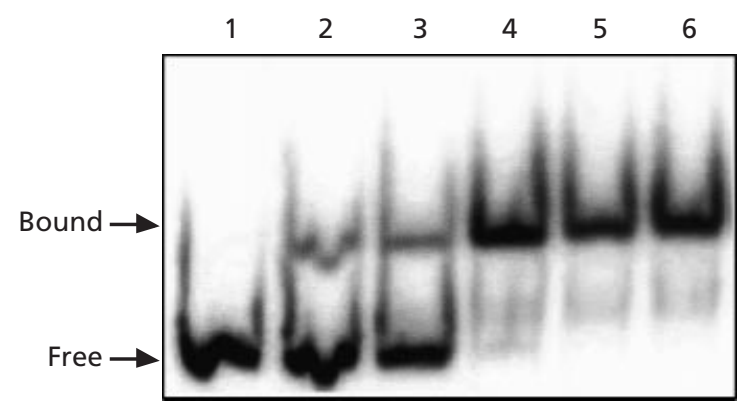

Fig. 4. Binding of Fur to the pvdS promoter. Fur purified from the MBP fusion was mixed with ${ }^{35}$ S-labelled DNA in the presence of $100 \mu \mathrm{M} \mathrm{MnCl}_{2}$. Protein concentrations were: lane 1, 0 ; lane 2, $50 \mathrm{nM}$; lane 3, $100 \mathrm{nM}$; lane 4, $150 \mathrm{nM}$; lane 5, $200 \mathrm{nM}$; lane $6,250 \mathrm{nM}$. Binding reactions were resolved on a $6 \%$ native polyacrylamide gel and were visualized by phosphorimaging. The mobilities of the free and protein-bound DNA species are indicated.

ture of the protein, with the tyrosine hydroxyl involved in a hydrogen bond that also shifts the tyrosine UV absorption to the red (Dietze et al., 1996; Groen et al., 1996; Soengas et al., 1997). The fluorescence emission of Fur was completely quenched by $6 \mathrm{M} \mathrm{Gdn.HCl,} \mathrm{which}$ is consistent with its originating from a structural feature. In summary, these spectroscopic data confirm that (a) refolding of the Fur protein after $\mathrm{Gdn} . \mathrm{HCl}$ treatment returns it to its native state, and (b) the addition of four residues to the N-terminus of Fur does not have a gross effect on the secondary structure of Fur.

\section{DNA binding}

Gel retardation analysis with Fur purified from the MBP fusion confirmed that this protein preparation is active for binding to DNA containing a Fur box (from the $P$. aeruginosa pvdS promoter; Ochsner et al., 1995) in the presence of $\mathrm{Mn}^{2+}$ ions (Fig. 4). At similar protein concentrations, Fur failed to bind to a similarly sized fragment not containing a Fur box (data not shown), confirming that binding was specific. As has been observed previously for Fur proteins from different sources, binding was inhibited in the presence of relatively low concentrations of EDTA. This has usually been explained by suggesting that the chelating agent removes from the protein the metal ion that is the corepressor for Fur (in this case $\mathrm{Mn}^{2+}$ ). However, it has recently been suggested that, for the E. coli Fur, EDTA may act by directly inhibiting the ability of the protein to bind to DNA (Althaus et al., 1999). The two possibilities cannot easily be resolved in this case, but it is interesting to note that, at a similar Fur concentration, binding to the $p v d S$ Fur box was not inhibited by $1 \mathrm{mM}$ bipyridyl (data not shown).

\section{P. aeruginosa Fur does not contain a structural zinc}

The E. coli Fur protein is a zinc metalloprotein that contains a structural $\mathrm{Zn}^{2+}$ ion bound to a site that is distinct from the metal sensing site where $\mathrm{Fe}^{2+}$ binds (Jacquamet et al., 1998; Gonzalez de Peredo et al., 1999; Althaus et al., 1999). The metal-sensing site can also accommodate $\mathrm{Zn}^{2+}$, such that as-prepared Fur from E. coli can bind a total of two $\mathrm{Zn}^{2+}$ ions per monomer. Of these, one is easily removed by treatment with EDTA, whereas removal of the structural $\mathrm{Zn}^{2+}$ ion requires unfolding of the protein (Althaus et al., 1999). The refolded apoprotein can be reconstituted with either one or two $\mathrm{Zn}^{2+}$ ions. Ligands to the zinc are believed to include the essential residues Cys-92 and Cys-95, and, probably, two histidine residues (Jacquamet et al., 1998). It has been suggested (Zheleznova et al., 2000) that some Fur family members, such as the protein from $P$. aeruginosa, might not contain the structural $\mathrm{Zn}^{2+}$ ion. Cys-95 is not conserved in the $P$. aeruginos a Fur, yet this protein is able to bind $\mathrm{Zn}^{2+}$ as shown by its ability to bind to an immobilized $\mathrm{Zn}^{2+}$-affinity column. It was, therefore, of some interest to determine whether this protein also contains a structural $\mathrm{Zn}^{2+}$ ion.

Analysis of as-prepared P. aeruginosa Fur by electrothermal atomic absorption spectroscopy (EAAS) revealed the presence of a significant amount of zinc that varied in different preparations. Unlike the E. coli Fur, treatment with EDTA removed the bulk of this zinc, to yield protein containing $0.19 \mathrm{Zn}^{2+}$ ions per monomer. Treatment of the as-prepared Fur with a large excess of $\mathrm{ZnCl}_{2}$ followed by dialysis to remove unbound $\mathrm{Zn}^{2+}$ yielded protein containing $0.94 \mathrm{Zn}^{2+}$ ions per monomer as judged by EAAS, again unlike the E. coli protein, which binds two $\mathrm{Zn}^{2+}$ ions under similar conditions. The simplest interpretation of these results is that the $P$. aeruginosa Fur binds a single $\mathrm{Zn}^{2+}$ ion in the metalsensing site, and does not have the structural $\mathrm{Zn}^{2+}$ binding site found in the E. coli protein. This distinction is consistent with the absence of Cys-95 in the $P$. aeruginosa protein, and is indicative of a degree of structural diversity in the Fur family. Structural diversity does not seem to be reflected in mechanistic diversity, at least to the extent that the $P$. aeruginosa fur gene can complement an E. colifur mutant (Prince et al., 1993; and 
Table 1. $\beta$-Galactosidase activities directed by a chromosomal bfd-lacZ fusion in $\Delta$ fur and fur ${ }^{+}$strains transformed with plasmids expressing the $P$. aeruginosa Fur and its engineered derivatives

The data are means \pm standard errors calculated from duplicate assays performed on three independently grown cultures.

\begin{tabular}{|c|c|c|c|c|}
\hline \multirow[t]{2}{*}{ Strain } & \multirow[t]{2}{*}{ Plasmid } & \multicolumn{3}{|c|}{$\begin{array}{c}\beta \text {-Galactosidase activity (Miller units) in cultures grown } \\
\text { in M9 medium supplemented with: }\end{array}$} \\
\hline & & No suppl. & Iron & Bipyridyl \\
\hline JRG2653 ( $\Delta$ fur $)$ & pBR322 & $135 \pm 9$ & $126 \pm 10$ & $123 \pm 5$ \\
\hline JRG2652 (fur $\left.{ }^{+}\right)$ & pBR322 & $34 \pm 7$ & $5 \pm 1$ & $56 \pm 6$ \\
\hline JRG2653 & pPAD24 (wt Fur) & $63 \pm 7$ & $21 \pm 9$ & $85 \pm 9$ \\
\hline JRG2653 & pPAD24-C92S & $29 \pm 6$ & $21 \pm 6$ & $94 \pm 2$ \\
\hline JRG2653 & pPAD24-C92A & $18 \pm 5$ & $10 \pm 1$ & $62 \pm 23$ \\
\hline JRG2653 & pPAD24-H86A & $79 \pm 6$ & $46 \pm 4$ & $80 \pm 14$ \\
\hline JRG2653 & pPAD24-H87A & $177 \pm 35$ & $155 \pm 25$ & $70 \pm 12$ \\
\hline JRG2653 & pPAD24-D88A & $134 \pm 11$ & $82 \pm 8$ & $69 \pm 13$ \\
\hline JRG2653 & pPAD24-H89A & $187 \pm 77$ & $211 \pm 64$ & $83 \pm 13$ \\
\hline
\end{tabular}

see below). Addition of a $\mathrm{ZnCl}_{2}$ solution to metal-free Fur did not produce significant changes to the $\mathrm{CD}$ or fluorescence spectra of the protein (data not shown), consistent with $\mathrm{Zn}^{2+}$ binding not causing large-scale conformational changes affecting the chromophores giving rise to the spectroscopic effects.

\section{$P$. aeruginosa Fur forms disulfide-linked dimers}

SDS-PAGE analysis of $P$. aeruginosa Fur showed that in the presence of DTT it behaves as a monomer, while in the absence of DTT a mixture of monomeric and dimeric species was seen (data not shown), with the relative amounts being batch-dependent. These data suggested that Cys-92 (the only cysteine in the protein) forms intermolecular disulfide bonds on air-oxidation, with freshly prepared protein having less of the dimer form than older preparations. This was confirmed by showing that Fur alkylated with iodoacetamide was unable to dimerize in the absence of DTT (data not shown). In a mass spectroscopic analysis of the E. coli Fur, no evidence for the occurrence of disulfide-bridged dimers was found (Michaud-Soret et al., 1997).

\section{Mutational analysis of $\boldsymbol{P}$. aeruginosa Fur}

The fur gene of $P$. aeruginosa is believed to be essential (Hassett et al., 1996), so it is difficult to evaluate the phenotypes associated with mutant alleles in a null background. The $P$. aeruginosa fur gene was originally cloned by complementation of an E. coli mutant (Prince et al., 1993), and P. aeruginosa Fur can bind to an E. coli Fur box in vitro (Ochsner et al., 1995). Hence, it was reasoned that it should be possible to examine activity of the $P$. aeruginosa Fur in the heterologous E. coli background. Therefore, a reporter system was developed in which the $P$. aeruginosa fur gene was expressed in a strain of E. coli (JRG2653) mutant for the endogenous fur gene and containing a chromosomal fusion of the Fur-regulated $b f d$ promoter to lacZ. The $b f d$ gene is linked to the $b f r$ gene of E. coli, encodes a [2Fe-2S] protein, and is repressed by Fur in response to iron (Andrews et al., 1989; Garg et al., 1996; Stojiljkovic et al., 1994). Measurement of $\beta$-galactosidase activity confirmed that the $P$. aeruginosa fur gene complements the E. coli fur mutant, and that the complemented strain shows iron-regulated expression of the $b f d$ promoter (Table 1). Repression is less tight than that seen with the chromosomal E. coli fur gene (in JRG2652), which may reflect either poor expression of the $P$. aeruginosa fur gene or a reduced activity of the heterologous regulator. The E. coli fur mutant has a pleiotropic phenotype that includes the overproduction of siderophores and an inability to grow on succinate as the sole source of carbon and energy (Hantke, 1987). Both of these phenotypes were also complemented by the $P$. aeruginosa gene. The reporter system was then used to assay the consequences of substituting the single cysteine residue of $P$. aeruginosa Fur with either serine or alanine. Both mutants were able to act as repressors of the $b f d$ promoter (Table 1), indicating that Cys-92 is dispensable for the activity of $P$. aeruginosa Fur. This conclusion was supported by the observation that both mutants restored growth on succinate and siderophore production to wild-type patterns (data not shown). Interestingly, the two cysteine mutants both seem to work better as repressors in the presence of the trace amounts of iron present in unsupplemented M9 medium than does the wild-type $P$. aeruginosa Fur (Table 1 ).

In sequence alignments of Fur proteins, there is a highly conserved $\mathrm{HHDH}$ motif in the central region of the protein (residues 86 to 89 in the $P$. aeruginosa protein). These four residues were substituted with alanine, and the mutants evaluated for their ability to repress the $b f d$ promoter in response to iron (Table 1). Proteins with 
substitutions H87A and H89A were inactive as repressors, suggesting that these histidines are essential for $P$. aeruginosa Fur activity. Accordingly, genes expressing these proteins also failed to restore growth on succinate, and repression of the synthesis of siderophores (data not shown). Proteins with substitutions H86A and D88A retained partial ability, as judged by their ability to regulate $b f d$ (Table 1$)$. Strains expressing these partially active proteins overexpressed siderophores and showed a reduced ability to grow on succinate.

Substitution of each of the three histidines (His-85, His86 and His-89) with leucine in the E. coli protein had surprisingly little effect on Fur activity in vivo (Coy et al., 1994). On the other hand, substitution of His-89 (E. coli numbering) with leucine led to loss of activity of the Vibrio cholerae Fur (Lam et al., 1994), which is consistent with the phenotype of the H89A mutant of $P$. aeruginosa Fur (Table 1). Substitution of His-90 of the $S$. typhimurium Fur (equivalent to H89 of the E. coli protein) with arginine eliminated iron-mediated repression but had no effect on the role of Fur in the acid tolerance response (Hall \& Foster, 1996). Although the fur gene of $P$. aeruginosa is thought to be essential (Hassett et al., 1996), some fur alleles with altered phenotypes have been characterized. Manganese resistance has been used as a screen for the isolation of fur alleles in $P$. aeruginosa, and amongst several characterized were two mutants with substitutions of arginine and tyrosine at His-86 (Barton et al., 1996). Strains carrying these mutations showed constitutive expression of siderophores but retained iron-regulation of exotoxin A expression, suggesting only a partial loss of Fur activity (Barton et al., 1996). This phenotype is consistent with the retention of some activity for the H86A mutant reported here.

Clearly much remains to be learned about the structure and mechanism of the Fur proteins. Future work will be directed towards exploiting the improved expression systems described in this report, with the ultimate goal of establishing the three-dimensional structure of the $P$. aeruginosa Fur.

\section{ACKNOWLEDGEMENTS}

We are grateful to Simon Andrews and Richard James for providing strains, to Rick Evans-Gowing and Andrew Leech for assistance with analytical procedures, and to Rachel Paley for help with the electrothermal atomic absorption spectroscopy. This work was supported by the EPSRC and the University of East Anglia, through provision of studentships for A.C.L. and P.A.D., respectively, and by BBSRC funding of the UEA Centre for Metalloprotein Spectroscopy and Biology.

\section{REFERENCES}

Althaus, E. W., Outten, C. E., Olson, K. E., Cao, H. \& O'Halloran, T. V. (1999). The ferric uptake regulation (Fur) repressor is a zinc metalloprotein. Biochemistry 38, 6559-6569.

Andrews, S. C., Harrison, P. M. \& Guest, J. R. (1989). Cloning, sequencing, and mapping of the bacterioferritin gene $(b f r)$ of Escherichia coli K12. J Bacteriol 171, 3940-3947.
Barton, H. A., Johnson, Z., Cox, C. D., Vasil, A. I. \& Vasil, M. L. (1996). Ferric uptake regulator mutants of Pseudomonas aeruginosa with distinct alterations in the iron-dependent repression of exotoxin A and siderophores in aerobic and microaerobic environments. Mol Microbiol 21, 1001-1017.

Bsat, N. \& Helmann, J. D. (1999). Interaction of Bacillus subtilis Fur (ferric uptake repressor) with the $d h b$ operator in vitro and in vivo. J Bacteriol 181, 4299-4307.

Chai, W. \& Stewart, v. (1998). NasR, a novel RNA-binding protein, mediates nitrate-responsive transcription antitermination of the Klebsiella oxytoca M5al nasF operon leader in vitro. J Mol Biol 283, 339-351.

Coy, M. \& Neilands, J. B. (1991). Structural dynamics and functional domains of the Fur protein. Biochemistry 30, 82018210.

Coy, M., Doyle, C., Besser, J. \& Neilands, J. B. (1994). Site-directed mutagenesis of the ferric uptake regulation gene of Escherichia coli. Biometals 7, 292-298.

Dietze, E. C., Wang, R. W., Lu, A. Y. H. \& Atkins, W. M. (1996). Ligand effects on the fluorescence properties of tyrosine-9 in alpha 1-1 glutathione S-transferase. Biochemistry 35, 6745-6753.

Escolar, L., Perez-Martin, J. \& de Lorenzo, V. (1999). Opening the iron box: transcriptional metalloregulation by the Fur protein. J Bacteriol 181, 6223-6229.

Garg, R. P., Vargo, C. J., Cui, X. \& Kurtz, D. M., Jr (1996). A [2Fe$2 \mathrm{~S}$ ] protein encoded by an open reading frame upstream of the Escherichia coli bacterioferritin gene. Biochemistry 35, 6297-6301.

Gill, S. C. \& von Hippel, P. H. (1989). Calculation of protein extinction coefficients from amino acid sequence data. Anal Biochem 182, 319-326.

Gonzalez de Peredo, A., Saint-Pierre, C., Adrait, A., Jacquamet, L., Latour, J. M., Michaud-Soret, I. \& Forest, E. (1999). Identification of the two zinc-bound cysteines in the ferric uptake regulation protein from Escherichia coli: chemical modification and mass spectrometry analysis. Biochemistry 38, 8582-8589.

Groen, B. H., Bloemendal, M., Mulders, J. W. M., Hadden, J. M., Chapman, D., Van Stokkum, I. H. M. \& Van Grondelle, R. (1996). Spectroscopic characterization of recombinant follicle stimulating hormone. Spectrochim Acta 52, 1331-1346.

Hall, H. K. \& Foster, J. W. (1996). The role of Fur in the acid tolerance response of Salmonella typhimurium is physiologically and genetically separable from its role in iron acquisition. J Bacteriol 178, 5683-5691.

Hantke, K. (1987). Selection procedure for deregulated iron transport mutants (fur) in Escherichia coli K12: fur not only affects iron metabolism. Mol Gen Genet 210, 135-139.

Hassett, D. J., Sokol, P. A., Howell, M. L., Ma, J. F., Schweizer, H. T., Ochsner, U. \& Vasil, M. L. (1996). Ferric uptake regulator (Fur) mutants of Pseudomonas aeruginosa demonstrate defective siderophore-mediated iron uptake, altered aerobic growth, and decreased superoxide dismutase and catalase activities. J Bacteriol 178, 3996-4003.

Hutchings, M. I., Shearer, N., Wastell, S., van Spanning, R. J. M. \& Spiro, S. (2000). Heterologous NNR-mediated nitric oxide signaling in Escherichia coli. J Bacteriol 182, 6434-6439.

Jacquamet, L., Aberdam, D., Adrait, A., Hazemann, J. L., Latour, J. M. \& Michaud-Soret, I. (1998). X-ray absorption spectroscopy of a new zinc site in the Fur protein from Escherichia coli. Biochemistry 37, 2564-2571.

Ko, Y. H., Thomas, P. J., Delannoy, M. R. \& Pedersen, P. L. (1993). The cystic fibrosis transmembrane conductance regulator. Over- 
expression, purification, and characterization of wild type and delta F508 mutant forms of the first nucleotide binding fold in fusion with the maltose-binding protein. J Biol Chem 268, 24330-24338.

Lakowicz, J. R. (1983). Principles of Fluorescence Spectroscopy. New York: Plenum Press.

Lam, M. S., Litwin, C. M., Carroll, P. A. \& Calderwood, S. B. (1994). Vibrio cholerae fur mutations associated with loss of repressor activity: implications for structural-functional relationships of Fur. J Bacteriol 176, 5108-5115.

Leoni, L., Ciervo, A., Orsi, N. \& Visca, P. (1996). Iron-regulated transcription of the $p v d A$ gene in Pseudomonas aeruginosa: effect of Fur and PvdS on promoter activity. J Bacteriol 178, 2299-2313.

Li, J., Kustu, S. \& Stewart, V. (1994). In vitro interaction of nitrateresponsive regulatory protein NarL with DNA target sequences in the $f d n G$, narG, narK and $f r d A$ operon control regions of Escherichia coli K-12. J Mol Biol 241, 150-165.

Litwin, M. \& Calderwood, S. B. (1993). Role of iron in regulation of virulence genes. Clin Microbiol Rev 6, 137-149.

Massé, E. \& Gottesman, S. (2002). A small RNA regulates the expression of genes involved in iron metabolism in Escherichia coli. Proc Natl Acad Sci U S A 99, 4620-4625.

Michaud-Soret, I., Adrait, A., Jaquinod, M., Forest, E., Touati, D. \& Latour, J.-M. (1997). Electrospray ionization mass spectrometry analysis of the apo- and metal-substituted forms of the Fur protein. FEBS Lett 413, 473-476.

Miller, J. H. (1992). A Short Course in Bacterial Genetics. Cold Spring Harbor, NY: Cold Spring Harbor Laboratory.

Ochsner, U. A., Vasil, A. I. \& Vasil, M. L. (1995). Role of the ferric uptake regulator of Pseudomonas aeruginosa in the regulation of siderophores and exotoxin A expression: purification and activity on iron-regulated promoters J Bacteriol 177, 7194-7201.

Ochsner, U. A., Johnson, Z., Lamont, I. L., Cunliffe, H. E. \& Vasil, M. L. (1996). Exotoxin A production in Psendomonas aeruginosa requires the iron-regulated $p v d S$ gene encoding an alternative sigma factor. Mol Microbiol 21, 1019-1028.

Pace, C. N. \& Scholtz, J. M. (1997). Measuring the conformational stability of a protein. In Protein Structure: a Practical Approach, 2nd edn, pp. 299-321. Edited by T. E. Creighton. Oxford: IRL Press.

Prince, R. W., Cox, C. D. \& Vasil, M. L. (1993). Coordinate regulation of siderophore and exotoxin A production: molecular cloning and sequencing of the Pseudomonas aeruginosa fur gene. J Bacteriol 175, 2589-2598.

Ratledge, C. \& Dover, L. G. (2000). Iron metabolism in pathogenic bacteria. Annu Rev Microbiol 54, 881-941.

Santoro, M. M. \& Bolen, D. W. (1988). Unfolding free energy changes determined by the linear extrapolation method. 1. Unfolding of phenylmethanesulfonyl $\alpha$-chymotrypsin using different denaturants. Biochemistry 27, 8063-8068.

Soengas, M. S., Mateo, C. R., Salas, M., Acuña, A. U. \& Gutiérrez, C. (1997). Structural features of $\phi 29$ single-stranded DNA-binding protein. I. Environment of tyrosines in terms of complex formation with DNA. J Biol Chem 272, 295-302.

Stojiljkovic, I. \& Hantke, K. (1995). Functional domains of the Escherichia coli ferric uptake regulator protein (Fur). Mol Gen Genet 247, 199-205.

Stojiljkovic, I., Baumler, A. J. \& Hantke, K. (1994). Fur regulon in gram-negative bacteria. Identification and characterization of new iron-regulated Escherichia coli genes by a Fur titration assay. J Mol Biol 236, 531-545.

Vasil, M. L. \& Ochsner, U. A. (1999). The response of Pseudomonas aeruginosa to iron: genetics, biochemistry and virulence. Mol Microbiol 34, 399-413.

Wilderman, P. J., Vasil, A. I., Johnson, Z., Wilson, M. J., Cunliffe, H. E., Lamont, I. L. \& Vasil, M. L. (2001). Characterization of an endoprotease (PrpL) encoded by a PvdS-regulated gene in Pseudomonas aeruginosa. Infect Immun 69, 5385-5394.

Zheleznova, E. L., Crosa, J. H. \& Brennan, R. G. (2000). Characterization of the DNA- and metal-binding properties of Vibrio anguillarum Fur reveals conservation of a structural $\mathrm{Zn}^{2+}$ ion. J Bacteriol 182, 6264-6267.

Received 19 April 2002; revised 3 May 2002; accepted 13 May 2002. 